\title{
Comparative Analysis of Neurogenesis in the Central Olfactory Pathway of Adult Decapod Crustaceans by In Vivo BrdU Labeling
}

\author{
MANFRED SCHMIDT ${ }^{1} * *$ AND STEFFEN HARZSCH ${ }^{2}$ \\ ${ }^{1}$ Zoologisches Institut und Zoologisches Museum, Neurophysiologie, Universität Hamburg, and Institut \\ für Biologie, Technische Universität Berlin, Germany; and ${ }^{2}$ Fakultät für Biologie, Neuroanatomie, \\ Universität Bielefeld, Germany
}

\begin{abstract}
To examine the distribution of neurogenesis in the central olfactory pathway of adult decapod crustaceans, we labeled, in vivo, six species of decapod crustaceans representing most infraorders (shrimps, spiny lobsters, clawed lobsters, crayfish, hermit crabs, true crabs) with the proliferation marker 5-bromo-2'-deoxyuridine (BrdU). In all tested species a group of small, neuron-like nuclei in the lateral soma clusters of the brain was labeled; the lateral soma clusters are composed of the cell bodies of ascending olfactory projection neurons. In only a few instances did groups of BrdU-positive nuclei also occur in the other soma clusters of the central olfactory pathway. In the spiny lobster (Panulirus argus), a group of small neuron-like nuclei was labeled in the medial soma clusters containing the cell bodies of local interneurons of the olfactory deutocerebrum. In the hermit crab (Pagurus bernhardus), and the true crab (Cancer pagurus), a group of small neuron-like nuclei was labeled in soma clusters located in the cycstalks. These soma clusters probably contain the cell bodies of local interneurons of the hemiellipsoid bodies, to which the olfactory projection neurons ascend. These results indicate that neurogenesis occurs among olfactory projection neurons in the adult brain. Among the other neuronal types of the central olfactory pathway, however, neurogenesis is restricted to specific taxa. The persistence of neurogenesis among the different neuronal types of the central olfactory pathway throughout adult life suggests an enormous structural plasticity of brain circuitry that may enable the long-
\end{abstract}

\footnotetext{
Received 4 November 1997; accepted 6 January 1999.

* To whom correspondence should be addressed. Universität Hamburg, Zoologisches Institut und Zoologisches Museum, Neurophysiologie, Martin-Luther-King-Platz 3, 20146 Hamburg, Germany. E-mail: mschmidt@zoologie.uni-hamburg.de
}

lived decapod crustaceans to adapt to changing olfactory environments.

\section{Introduction}

It was commonly believed that neurogenesis is rare, if not totally absent, in the central nervous system of most adult animals (e.g., Purves, 1988), although de novo generation of neurons occurs in the brain of adult birds (e.g., Paton and Nottebohm, 1984), fish (e.g., Raymond and Easter, 1983), and mammals (Kaplan and Hinds, 1977; Bayer, 1982; Kaplan et al., 1985; Crespo et al., 1986). During the last decade, the development of new techniques to label and culture proliferating cells fostered a surge of research that conclusively demonstrated neurogenesis in the adult mammalian brain (Corotto et al., 1993; Luskin, 1993; Okano et al., 1993; Morshead et al., 1994; Kuhn et al., 1996). Adult neurogenesis also occurs in the arthropod brain (Cayre $e t$ al., 1994; Cayre et al., 1996; Schmidt, 1997; Sandeman et al., 1998). Thus, neurogenesis in the adult brain is now known to be a continuous process that contributes significantly to the neuronal population of specific brain areas.

In the mammalian brain, two regions in particular acquire new neurons throughout adult life: the dentate gyrus of the hippocampus (Bayer, 1982; Crespo et al., 1986; Okano et al., 1993; Kuhn et al., 1996) and the olfactory bulb (Kaplan et al., 1985; Corotto et al., 1993; Luskin, 1993; Okano et al., 1993). In the dentate gyrus, new granule cells develop from progenitor cells in the subgranular region (Crespo et al., 1986; Okano et al., 1993; Kuhn et al., 1996). Although the rate of neurogenesis decreases significantly with age (Kuhn et al., 1996), the number of granule cells increases continuously (Crespo et al., 1986), indicating that cell death is rare. The olfactory bulb acquires local interneurons of dif- 
ferent types (granule cells, periglomerular cells) almost linearly with age, although many of the new neurons do not survive, indicating a substantial turnover (Kaplan et al., 1985; Corotto et al., 1993; Luskin, 1993; Okano et al., 1993). The new neurons in the olfactory bulb originate from constitutively proliferating cells in the subependymal zone of the lateral ventricles (Moreshead et al., 1994), some of which migrate rostrally along a highly restricted pathway (the rostral migratory stream) and differentiate into neurons upon reaching the olfactory bulb (Luskin, 1993).

Evidence for neurogenesis in the adult arthropod brain was obtained in diverse insect species and in two species of decapod crustaceans, Carcinus maenas (shore crab) and Cherax destructor (Australian crayfish) (Bieber and Fuldner, 1979; Technau, 1984; Cayre et al., 1994, 1996; Schmidt, 1997; Sandeman et al., 1998). As in mammals, in arthropods adult neurogenesis is restricted to or prominent in specific brain areas. In adult insects, only the mushroom bodies, which represent the second stage of the central olfactory pathway and mediate olfactory learning and memory (see reviews by Davis, 1993; Menzel et al., 1994), acquire new local interneurons, the Kenyon cells (Bieber and Fuldner, 1979; Technau, 1984; Cayre et al., 1994, 1996). Surprisingly, only in some insect species do adults show neurogenesis of Kenyon cells (fly: Drosophila melanogaster; crickets: Acheta domesticus, Gryllus himaculatus, Gryllomorpha dalmatina; beetles: Aleochara curtula, Tenebrio molitor, Zophobas spec., Harmonia axyridis), whereas other species (bee: Apis mellifera; locust: Locusta migratoria; cockroach: Periplaneta americana) do not (Bieber and Fuldner, 1979; Technau, 1984; Cayre et al., 1994, 1996; Fahrbach et al., 1995). In adult insects, neurogenesis appears to be driven by typically large neuroblasts or ganglion mother cells that continue to be mitotically active into the imaginal stage (Technau, 1984; Cayre et al., 1994, 1996).

Evidence for adult neurogenesis in decapod crustaceans occurs in the central olfactory pathway (Schmidt, 1997; Sandeman et al., 1998). In decapods, as in insects, this pathway is composed of two elements: bilateral glomerular neuropils of the deutocerebrum, where olfactory afferents transmit information onto local interneurons and projection neurons (antennal lobes in insects; olfactory lobes in decapods); and bilateral second-order neuropils of the protocerebrum, to which the projection neurons ascend (mushroom bodies in insects; hemiellipsoid bodies in decapods) (e.g., Boeckh et al., 1984; Blaustein et al., 1988; Mellon et al., 1992). In adult shore crabs (Carcinus maenas) and Australian crayfish (Cherax destructor), in vivo labeling with the thymidine analog 5-bromo-2'-deoxyuridine (BrdU) demonstrated neuronal proliferation in the lateral soma clusters (LC) containing the somata of olfactory projection neurons (Schmidt, 1997; Sandeman et al., 1998). In Carcinus maenas, neuronal proliferation also occurred in clusters of cell bodies associated with the hemiellipsoid bodies (HBC) but not in the medial soma clusters (MC) containing the somata of local interneurons restricted to the olfactory deutocerebrum (Schmidt, 1997). In late juveniles of Cherax destructor, however, proliferation was detected in the MC (Sandeman et al., 1998). In both analyzed species, proliferation in the LC is associated with a continuous linear increase in the number of mature olfactory projection neurons throughout the life span of postlarval animals (Schmidt, 1997; Sandeman et al., 1998). In Carcinus maenas, the proliferating cells in the LC and the HBC are tightly packed in a very restricted area close to the respective neuropil, thus delineating these areas as proliferative zones. In location and morphology, the proliferating cells deviate considerably from typical neuroblasts or ganglion mother cells that are still mitotically active in the LCs of early crab juveniles (Harzsch and Dawirs, 1996). 'This indicates that neurogenesis in the central olfactory pathway of adult shore crabs occurs by a different mechanism than during embryonic and larval development.

In this study we ask whether the neurogenesis that has been observed in the central olfactory pathway of adult shore crabs (Carcinus maenas) and Australian crayfish (Cherax destructor) can be generalized to other decapod crustaceans. In vivo labeling with BrdU in six species representing most of the important decapod taxa (Caridea = shrimps, Palinura $=$ spiny lobsters, Astacidea $=$ clawed lobsters and crayfish, Anomura $=$ hermit crabs, Brachyura $=$ true crabs) revealed that proliferation among olfactory projection neurons is a common phenomenon in adult decapods. Significant differences between species exist in the occurrence of neurogenesis among local interneurons of the olfactory deutocerebrum and among neurons that probably represent local interneurons of the hemiellipsoid bodies. We conclude that the central olfactory pathway of decapod crustaceans retains a lifelong structural plasticity, whose regulation and physiological significance remains to be elucidated.

\section{Materials and Methods}

Experiments were performed on adult, sexually mature specimens (and in case of Panulirus argus, also on late juveniles) of six species of decapod crustaceans (Table I). All animals were kept in tanks with running seawater or fresh water without feeding for at least 2 days prior to the experiments.

For in vivo labeling, 5-bromo-2'-deoxyuridine (BrdU) was injected into the hemolymph of experimental specimens (5 milligrams of BrdU per 100 gram of body weight in a $0.5 \% \mathrm{BrdU}$ solution in the appropriate saline). After survival times of 6 to $24 \mathrm{~h}$, the brains of the animals were fixed with Bodian \# 2 fixative $(90 \mathrm{ml} 80 \%$ ethanol, $5 \mathrm{ml}$ formol, $5 \mathrm{ml}$ glacial acetic acid), for $1-4 \mathrm{~h}$ at room temperature. After rinsing in $0.1 \mathrm{M}$ Sörensen phosphate buffer (SPB), the brains were embedded in gelatin and cut on a 
Table I

Summary of decapod crustacean species investigated

\begin{tabular}{|c|c|c|c|c|c|c|c|}
\hline \multirow{2}{*}{$\begin{array}{l}\text { Scientific } \\
\text { name }\end{array}$} & \multirow[b]{2}{*}{ Trivial name } & \multicolumn{2}{|c|}{ Systematic status } & \multirow[b]{2}{*}{$n \dagger$} & \multirow{2}{*}{$\begin{array}{c}\text { Carapace } \\
\text { length }(\mathrm{cm})\end{array}$} & \multirow{2}{*}{$\begin{array}{l}\text { Weight } \\
(\mathrm{g})\end{array}$} & \multirow[b]{2}{*}{ Source of material } \\
\hline & & Infraorder* & Family & & & & \\
\hline $\begin{array}{l}\text { Sicyonia } \\
\text { brevirostris }\end{array}$ & Rock shrimp & $\begin{array}{l}\text { Penaeidea } \\
\text { [Caridea] }\end{array}$ & Sicyonidae & 3 & - & $15-17$ & $\begin{array}{l}\text { Dr. J. Nunez, Whitney Laboratory, } \\
\text { University of Florida }\end{array}$ \\
\hline $\begin{array}{l}\text { Panulirus } \\
\text { argus }\end{array}$ & $\begin{array}{l}\text { Caribbean spiny } \\
\text { lobster }\end{array}$ & $\begin{array}{l}\text { Palinura } \\
\text { [Achelata] }\end{array}$ & Palinuridae & 7 & $2.8-6.0$ & $15-208$ & $\begin{array}{l}\text { Dr. B. W. Ache, Whitney Laboratory, } \\
\text { University of Florida }\end{array}$ \\
\hline $\begin{array}{l}\text { Homarus } \\
\text { americanus }\end{array}$ & American lobster & $\begin{array}{l}\text { Astacidea } \\
\text { [Homarida] }\end{array}$ & Homaridae & 5 & $11.0-13.5$ & $500-750$ & Commercial supplier \\
\hline $\begin{array}{l}\text { Cherax } \\
\text { destructor }\end{array}$ & Australian crayfish & $\begin{array}{l}\text { Astacidea } \\
\text { [Astacida] }\end{array}$ & Parastacidae & 3 & $5.2-5.4$ & $50-61$ & Commercial supplier \\
\hline $\begin{array}{l}\text { Pagurus } \\
\quad \text { bernhardus }\end{array}$ & Hermit crab & $\begin{array}{l}\text { Anomura } \\
\text { [Anomala] }\end{array}$ & Paguridae & 5 & $1.6-2.8$ & $3.5-29.7$ & Biologische Anstalt Helgoland \\
\hline $\begin{array}{l}\text { Cancer } \\
\text { pagurus }\end{array}$ & Common crab & $\begin{array}{l}\text { Brachyura } \\
\text { [Brachyura] }\end{array}$ & Cancridae & 5 & $10.2-16.0$ & $167-688$ & Biologische Anstalt Helgoland \\
\hline
\end{tabular}

* Name according to Gruner (1993), followed [in brackets] by name according to terminology proposed in most recent investigations of decapod phylogeny by Sandeman et al., (1993) and Scholtz and Richter (1995).

$\dagger n=$ number of specimens examined.

vibratome into serial sections with a thickness of 70 or 100 $\mu \mathrm{m}$. After degelatinization in a warm water bath, incubation in $2 \mathrm{~N} \mathrm{HCl}$ for $20 \mathrm{~min}$, and rinsing $(4 \times 15 \mathrm{~min})$ in SPB, the free-floating sections were incubated overnight in anti-BrdU ("Cell Proliferation Kit" from Boehringer or anti-BrdU containing nucleases from Amersham). Subsequently, sections were rinsed in SPB $(4 \times 30 \mathrm{~min})$ and incubated for $4 \mathrm{~h}$ in goat anti-mouse CY3-labeled secondary antibody (Jackson Immunoresearch) diluted 1:100 in SPB. After final rinsing in SPB $(4 \times 30 \mathrm{~min})$, the labeled sections were coverslipped in glycerol/SPB.

Sections were viewed and photographed using a microscope with bright-field optics and epifluorescence (Olympus BH-2 or IX-50). Despite increased section thickness ( $70 \mu \mathrm{m}$ compared to the $20-\mu \mathrm{m}$-thick cryostat sections normally used in BrdU immunostainings of mammalian tissue), no problems with antibody penetration were encountered. Intensely labeled nuclei were detectable throughout the entire thickness of the vibratome sections. The method we used here for the in vivo BrdU-labeling was the same as in a previous study (Schmidt, 1997), where it was shown to be highly reliable since in all 16 shore crabs (Carcinus maenas) treated by this method, somata in the LC were distinctly labeled.

\section{Results}

In vivo labeling with BrdU resulted in the clear visualization of nuclei in soma clusters of the central olfactory pathway in most of the specimens. All tested species showed labeling of nuclei in the paired lateral soma clusters (LC; soma cluster \# 10 according to Sandeman et al., 1992) of the olfactory deutocerebrum (Figs. 1; 2a, b; 3a; 4; 5a, b; $6 a)$. These clusters exclusively contain somata of ascending olfactory projection neurons (OPN). The BrdU-positive nuclei in the LC differed from other labeled nuclei that were present throughout almost all brain areas by their specific location, arrangement, and shape. The labeled nuclei in the LC always occurred as a tightly packed, string- or ball-like group that was located in the ventral part of the cluster directly adjacent to the neuropil of the olfactory lobe (OL). They were spherical and slightly smaller than were the

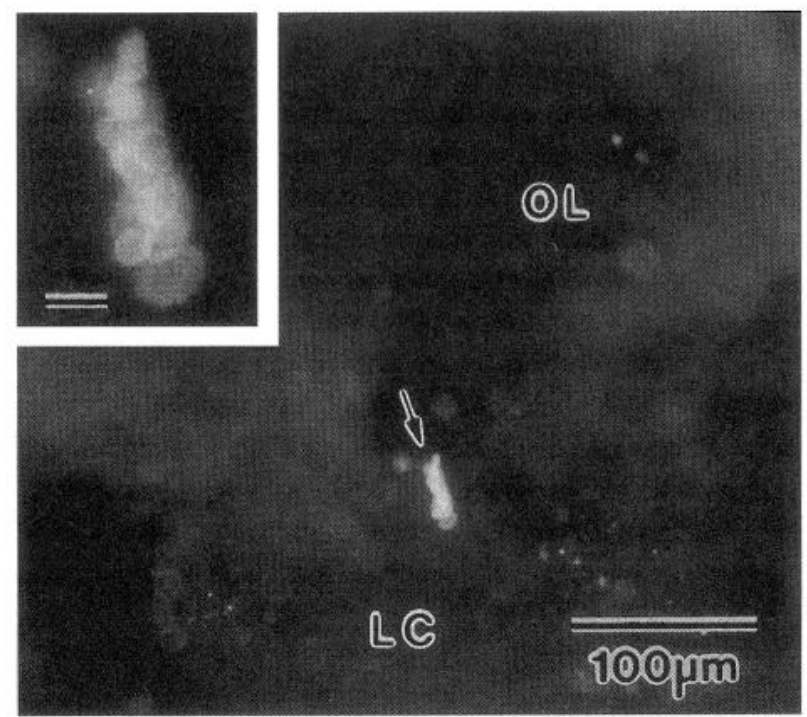

Figure 1. Proliferating cells in the central olfactory pathway of adult rock shrimp (Sicyonia brevirostris: Penaeidea [Caridea]; Sicyonidae) identified by in vivo BrdU-labeling. Light micrographs of vibratome sections. In the lateral soma cluster (LC) a compact, string-like group of small BrdU-positive nuclei (arrow) is located close to the neuropil of the olfactory lobe $(\mathrm{OL})$. Inset: higher magnification shows spherical, and hence neuronal shape of labeled somata. 

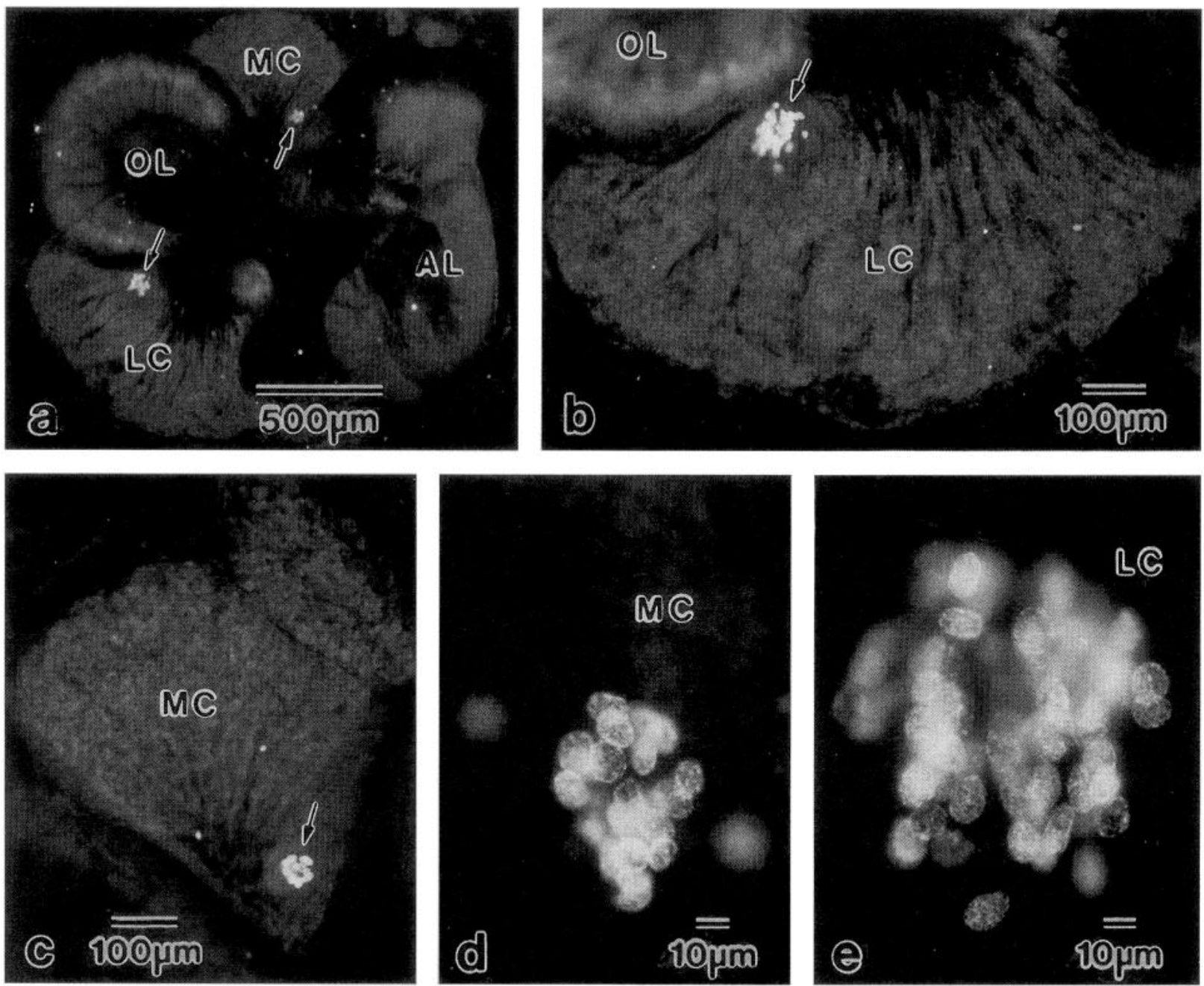

Figure 2. Proliferating cells in the central olfactory pathway of late juvenile (a-c; $49-57 \mathrm{~g}$ ) and adult (d, e; 140 g) spiny lobster (Panulirus argus: Palinura [Achelata]; Palinuridae) identified by in vivo BrdU-labeling. Light micrographs of vibratome sections. (a) Overview of olfactory deutocerebrum (hemibrain). In the lateral soma cluster (LC) and the medial soma cluster (MC), a compact group of small BrdU-positive nuclei (arrows) is located close to the neuropil of the olfactory lobe (OL). Note presence of the large accessory lobe (AL). (b, e) BrdU-positive nuclei in the lateral soma cluster at higher magnification. Note spherical and hence neuronal shape of labeled nuclei in e. (c, d) BrdU-positive nuclei in the medial soma cluster at higher magnification. Note spherical and hence neuronal shape of labeled nuclei in $\mathrm{d}$.

unlabeled nuclei of OPN somata located in the periphery of the LC (Fig. 2b, e).

For the species in which specimens of different size (and hence age) were tested (Panulirus argus, Cancer pagurus), only in Cancer pagurus did we find obvious differences in the number of BrdU-positive nuclei per LC between specimens. In Cancer pagurus, the LC of three large specimens (650-700 g and $c a .16 \mathrm{~cm}$ carapace width) showed no labeled somata or only some that were very weakly labeled (some nuclei belonging to other cell types were intensely labeled, showing that BrdU had been available for incorporation). However, typical groups of strongly BrdU-positive nuclei occurred in all LCs in two smaller, and hence younger, adults (160-200 $\mathrm{g}$ and $10-11 \mathrm{~cm}$ carapace width). In Panulirus argus (15-208 g and carapace length of 2.8-6 $\mathrm{cm}$ ), we detected no obvious difference in the number of BrdU-positive nuclei per LC.

The number of BrdU-positive nuclei per LC differed considerably among species. In Sicyonia brevirostris, only a few nuclei (less then 15) per LC were BrdU-positive (Fig. 1). In Cherax destructor (Fig. 4), as well as in Pagurus bernhardus (Fig. 5) and Cancer pagurus (Fig. 6), the number of BrdU-positive nuclei per LC was somewhat higher (20 to 40). In Homarus americanus (Fig. 3a), about 50 nuclei per LC, and in Panulirus argus (Fig. 2a, b, e), more than 80 nuclei per LC were BrdU-positive.

Of the species included in this study, two (Panulirus argus and Homarus americanus) showed proliferation not only in the LC but also in the paired medial soma cluster (MC; soma clusters \# 9 and 11 according to Sandeman et 

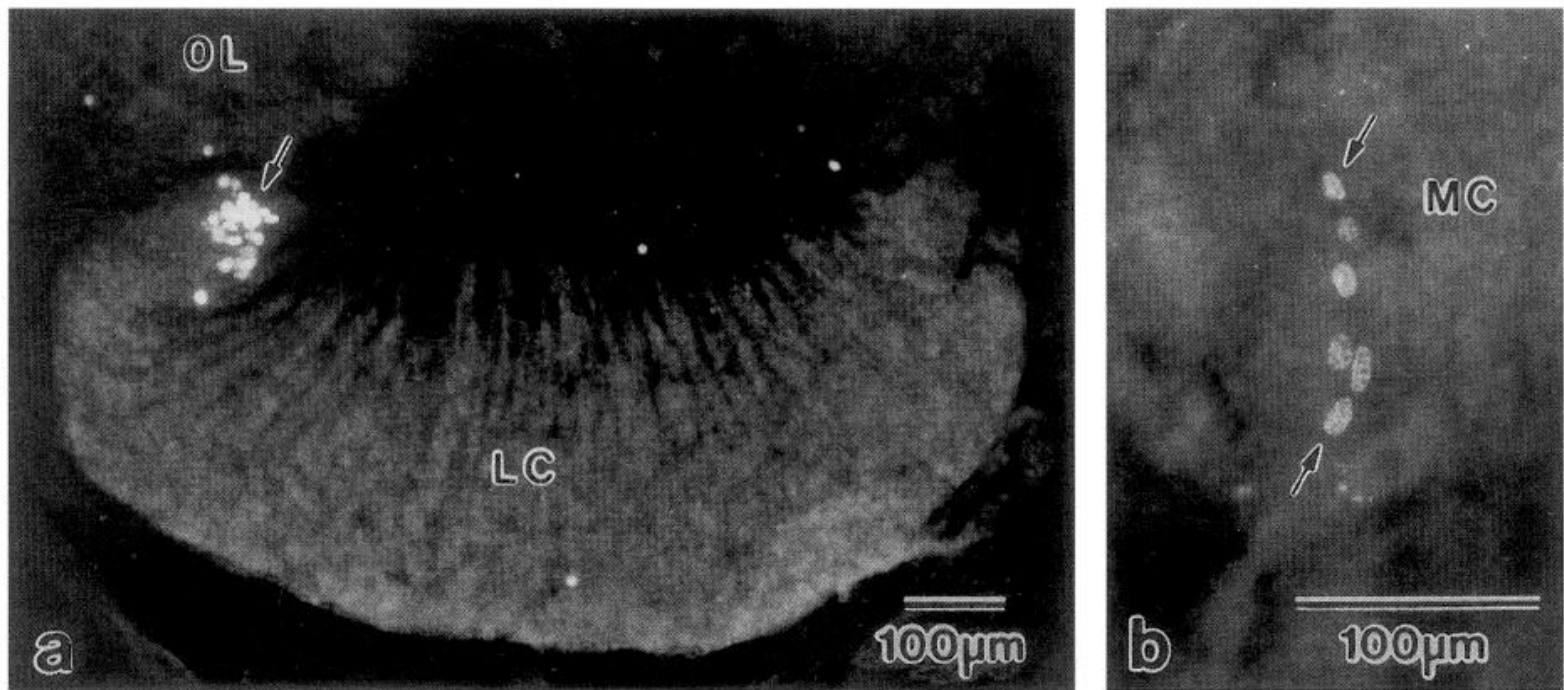

Figure 3. Proliferating cells in the central olfactory pathway of adult American lobster (Homarus americanus: Astacidea [Homarida]; Homaridae) identified by in vivo BrdU-labeling. Light micrographs of vibratome sections. (a) In the lateral soma cluster (LC), a compact group of small BrdU-positive nuclei (arrow) is located close to the neuropil of the olfactory lobe $(\mathrm{OL})$. (b) In the medial soma cluster $(\mathrm{MC})$ of this specimen, a string of slightly elongated nuclei is BrdU positive (arrows).

al., 1992) containing the cell bodies of local interneurons of the olfactory deutocerebrum (Figs. 2a, c, d, 3b). Only Panulirus argus showed a tightly packed group of BrdU-positive nuclei in the MCs in all tested specimens, which ranged from late juveniles to mid-sized sexually mature adults. In each case this group comprised 15-25 strongly labeled spherical nuclei that were slightly smaller than the nuclei of somata located in the periphery of the MC (Fig. 2c, d). The group of BrdU-positive nuclei was located in the ventralmost area of the MC adjacent to the neuropils of the olfac-

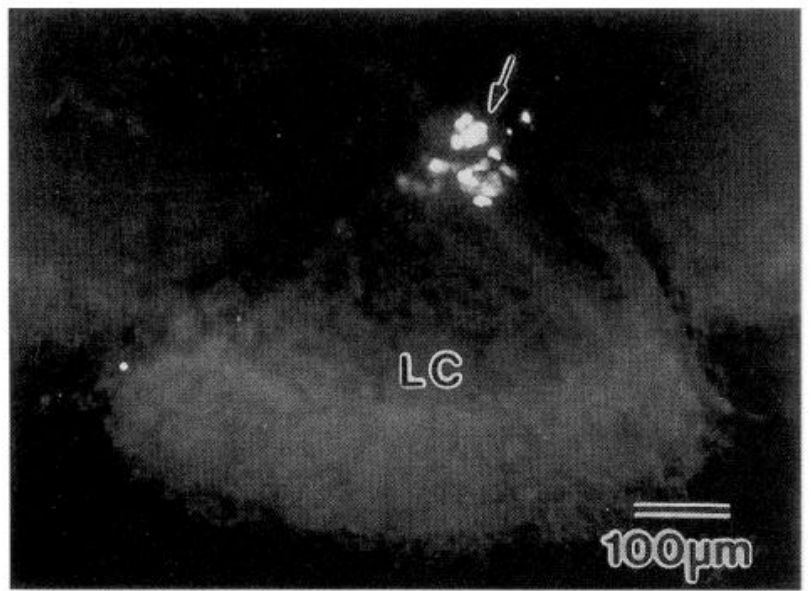

Figure 4. Proliferating cells in the central olfactory pathway of adult Australian crayfish (Cherax destructor: Astacidea [Astacida]; Parastacidae) identified by in vivo BrdU-labeling. Light micrograph of a vibratome section. A compact group of small BrdU-positive nuclei (arrow) is located in the LC close to the neuropils of the olfactory lobe and the accessory lobe. tory and accessory lobes (Fig. 2a, c). In Homarus americanus, evidence for proliferation in the MC occurred in only two of five tested specimens. The MCs of these two animals contained a group of about 10 strongly BrdU-positive nuclei that were slightly elongated and arranged in a string transversing the cluster from its innermost aspect to the periphery (Fig. 3b).

Two of the species included in this study, the hermit crab (Pagurus bernhardus) and the true crab (Cancer pagurus), possessed BrdU-positive nuclei arranged in an obvious group in the LC and in a paired soma cluster adjacent to the hemiellipsoid body (HBC). The morphology of the neurons whose somata constitute the HBCs has not yet been elucidated, and it remains unclear whether they represent local interneurons of the hemiellipsoid bodies. In Pagurus bernhardus, the eyestalks $(n=10)$ of all specimens had a group of 6-15 BrdU-positive nuclei in the HBC (Fig. 5c). In only two of the eyestalks of the three large specimens of Cancer pagurus did we find a cluster of BrdU-positive nuclei in the HBC. In contrast, the eyestalks $(n=4)$ of the two smaller specimens contained a cluster of BrdU-positive nuclei in the HBC. In each case, the number of BrdU-positive nuclei ranged from 20 to 30 per $\mathrm{HBC}$ (Fig. 6b). The BrdU-positive nuclei in the HBC of Pagurus bernhardus and Cancer pagurus were spherical and slightly smaller than the nuclei of unlabeled somata in the periphery of the HBC. In each case, the group of BrdU-positive nuclei was located close to the HB neuropil. None of the other species had a group of BrdU-positive nuclei present in the HBC. This negative result is supported best by the spiny lobster (Panulirus argus), where 13 eyestalks were analyzed, and the rock 

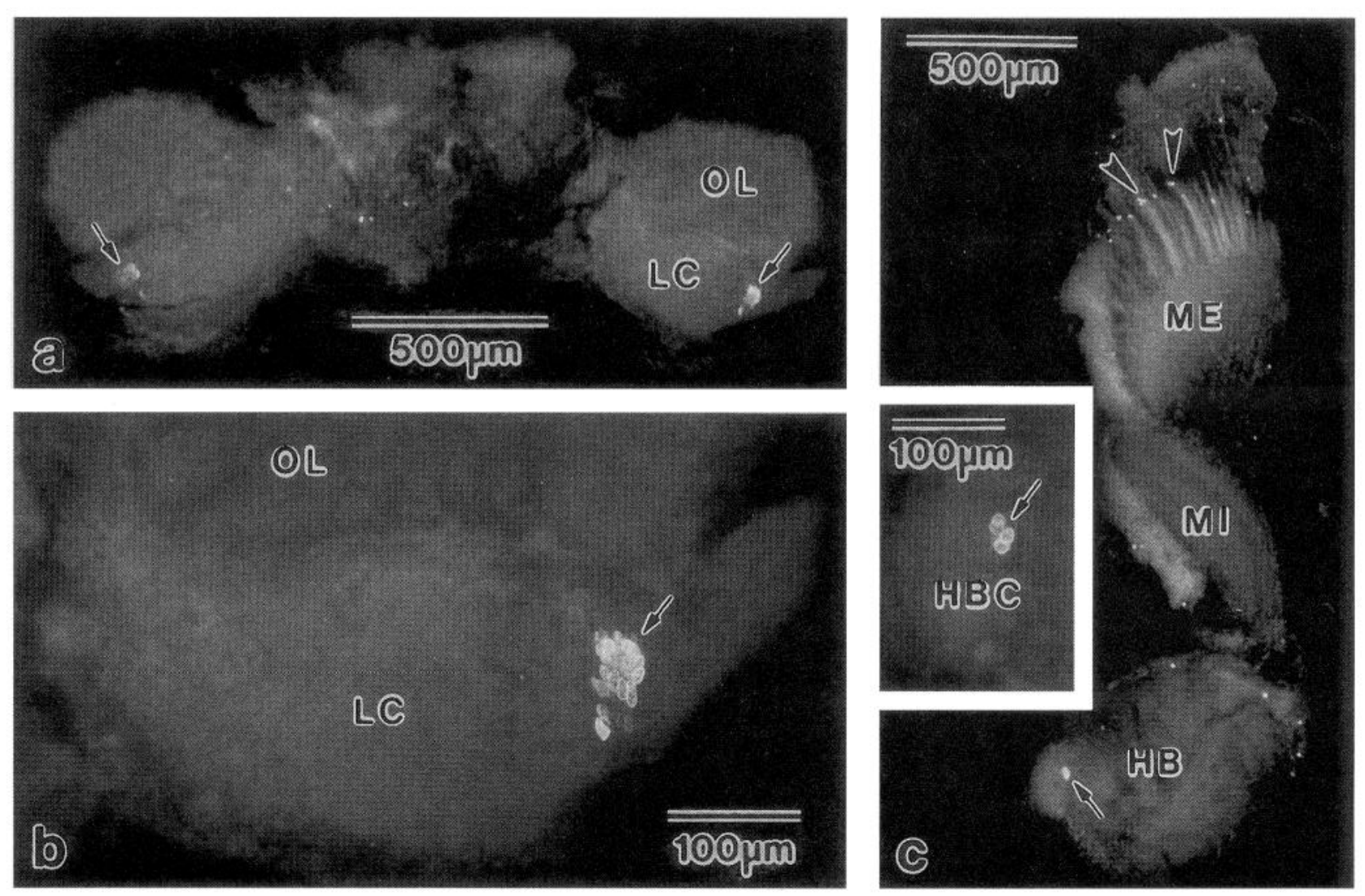

Figure 5. Proliferating cells in the central olfactory pathway of adult hermit crab (Pagurus bernhardus: Anomura [Anomala]; Paguridae) identified by in vivo BrdU-labeling. Light micrographs of vibratome sections. (a, b) Central brain. In the lateral soma clusters (LC), a compact group of small BrdU-positive nuclei (arrows) is located close to the neuropil of the olfactory lobe (OL). (c) Eyestalk ganglion. In the soma cluster (HBC) of the hemiellipsoid body (HB), a compact group of small BrdU-positive nuclei is located close to the HB neuropil. Note scattered BrdU-positive nuclei (arrowheads) in the soma clusters of visual neuropils (medulla interna = MI; medulla externa $=\mathrm{ME}$ ). Inset: Higher magnification shows shows spherical and hence neuronal shape of BrdU-positive nuclei.

shrimp (Sicyonia brevirostris), where 5 eyestalks were analyzed. However, in all tested species, very few nuclei located in the HBC were labeled in most specimens; the same was true for other soma clusters of the eyestalk ganglia, especially the soma clusters of the three visual neuropils. Most of these BrdU-positive nuclei were either flat and elongated, and thus probably represent glial cells; or they were more spherical but clearly associated with arterioles passing through the soma clusters, and thus probably represent connective tissue cells constituting the wall of these hemolymph vessels. But some nuclei in soma clusters were spherical and not obviously associated with arterioles; thus they might represent neuronal precursor cells.

\section{Discussion}

We demonstrate by in vivo labeling with BrdU that mitotic activity in the neuronal soma clusters of the central olfactory pathway appears to be a common feature of adult decapod crustaceans; this result corroborates and substan- tially extends previous findings for juvenile and adult shore crabs (Carcinus maenas) and for the Australian crayfish (Cherax destructor) (Schmidt, 1997; Sandeman et al., 1998). In all three studies the BrdU-positive nuclei in the soma clusters of the central olfactory pathway were small and almost spherical, and clearly resemble neurons. However, positive BrdU-labeling of neuron-like nuclei in soma clusters that are predominantly, but not exclusively, composed of neuronal cell bodies (the clusters also contain the somata of glial cells and of cells forming the walls of arterioles) is not conclusive evidence for the generation of new neurons, i.e., neurogenesis. BrdU-labeling could be explained in several alternative ways: differentiation of proliferating cells into non-neuronal cells, programmed cell death shortly after birth of new cells, or DNA synthesis without subsequent mitosis. In the case of Carcinus maenas, however, various lines of evidence rule out these alternatives and thus strongly support the notion that proliferation in the soma clusters of the central olfactory pathway indeed 

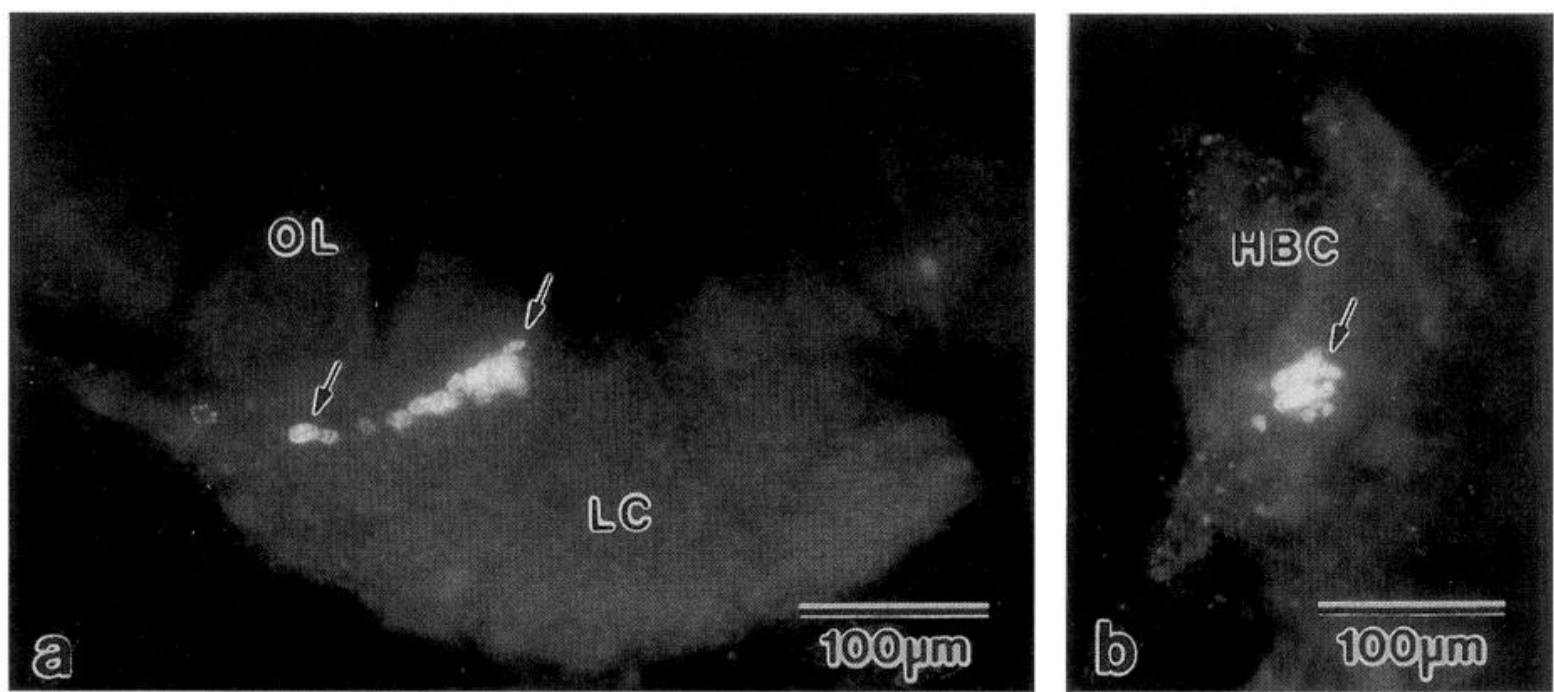

Figure 6. Proliferating cells in the central olfactory pathway of adult common crab (Cancer pagurus: Brachyura [Brachyura]; Cancridae) identified by in vivo BrdU-labeling. Light micrographs of vibratome sections. (a) Central brain. In the lateral soma cluster (LC), a compact group of small BrdU-positive nuclei (arrows) is located close to the neuropil of the olfactory lobe (OL), (b) Eyestalk ganglion. In the soma cluster (HBC) of the hemiellipsoid body, a compact group of small BrdU-positive nuclei is present (arrow).

reflects neurogenesis (Schmidt, 1997). This conclusion is substantially supported by the finding that in Carcinus maenas and in Cherax destructor, the olfactory projection neurons whose somata constitute the LCs increase continuously in number throughout juvenile and adult growth (Schmidt, 1997; Sandeman et al., 1998). Throughout juvenile and adult life the number of olfactory projection neurons doubles in Carcinus maenas (from ca. 24,000 to ca. 48,000 per brain: Schmidt, 1997), and it approximately triples in Cherax destructor (from ca. 60,000 to ca. 180,000 per brain: Sandeman et al., 1998). Thus, the generation of new olfactory projection neurons throughout juvenile and adult life appears to be well established in these species. The groups of proliferating cells in the respective soma clusters most likely reflect the cellular basis of this neuronal proliferation. We conclude that, at least for the LC, the occurrence of groups of BrdU-positive, neuron-like somata truly indicates neurogenesis, although a direct confirmation of this conclusion (for instance by double-labeling BrdU-positive cells with neuronal markers) is still lacking.

Another important issue is whether the occurrence of groups of BrdU-positive nuclei in the $\mathrm{MC}$ and the $\mathrm{HBC}$ can also be regarded as an indication of neurogenesis. At present the answer is uncertain, since counts of the respective neuron types have not yet been performed in the species we studied. Two lines of evidence support this assumption for the HBC. First, the BrdU-positive nuclei in the HBC are very similar in size, shape, and location (at the inside of the cluster, directly adjacent to the neuropil) to the BrdUpositive nuclei in the $\mathrm{LC}$, in all three species in which they were found (this study; Schmidt, 1997). Second, in Carcinus maenas, groups of BrdU-positive neuron-like nuclei were present in the $\mathrm{HBC}$ after a long post-injection survival time (1 month), ruling out the possibilities that newly born cells collectively either undergo programmed cell death or differentiate into non-neuronal cells (Schmidt, 1997). For the MC, only the very similar size, shape, and location (also at the inside of the cluster, directly adjacent to the neuropil) of the BrdU-positive nuclei to the BrdU-positive nuclei in the LC supports the assumption that mitotic activity as shown by the BrdU-labeling in this study reflects neurogenesis. In a strict sense this argument applies only to the spiny lobster (Panulirus argus), in which BrdU-positive nuclei were consistently present in the MC and were indeed indistinguishable from their counterparts in the LC in terms of the above mentioned criteria. However, in the American lobster (Homarus americanus), where we also observed BrdU-positive nuclei in the MC, the situation is not as clear. BrdU-positive nuclei forming a group were present in the MCs in only two of the five tested specimens. Furthermore, the labeled nuclei were slightly elongated compared to the BrdU-positive nuclei of the LC, and the group they formed was neither compact nor located close to the OL/AL neuropil (as in the spiny lobster). Therefore it remains questionable whether the proliferating cells in the $\mathrm{MC}$ of $\mathrm{Ho}$ marus americanus give rise to new neurons or to other cell types. The shape and arrangement of these BrdU-positive nuclei suggest that they might represent cells forming the wall of arterioles. Double labeling experiments with neuronal markers are necessary to clarify this point. Recently, the occurrence of BrdU-positive nuclei in the MC was reported for juveniles and adults of the Australian crayfish (Cherax destructor) (Sandeman et al., 1998). Here we could not reproduce this result in the three adult specimens tested, and 


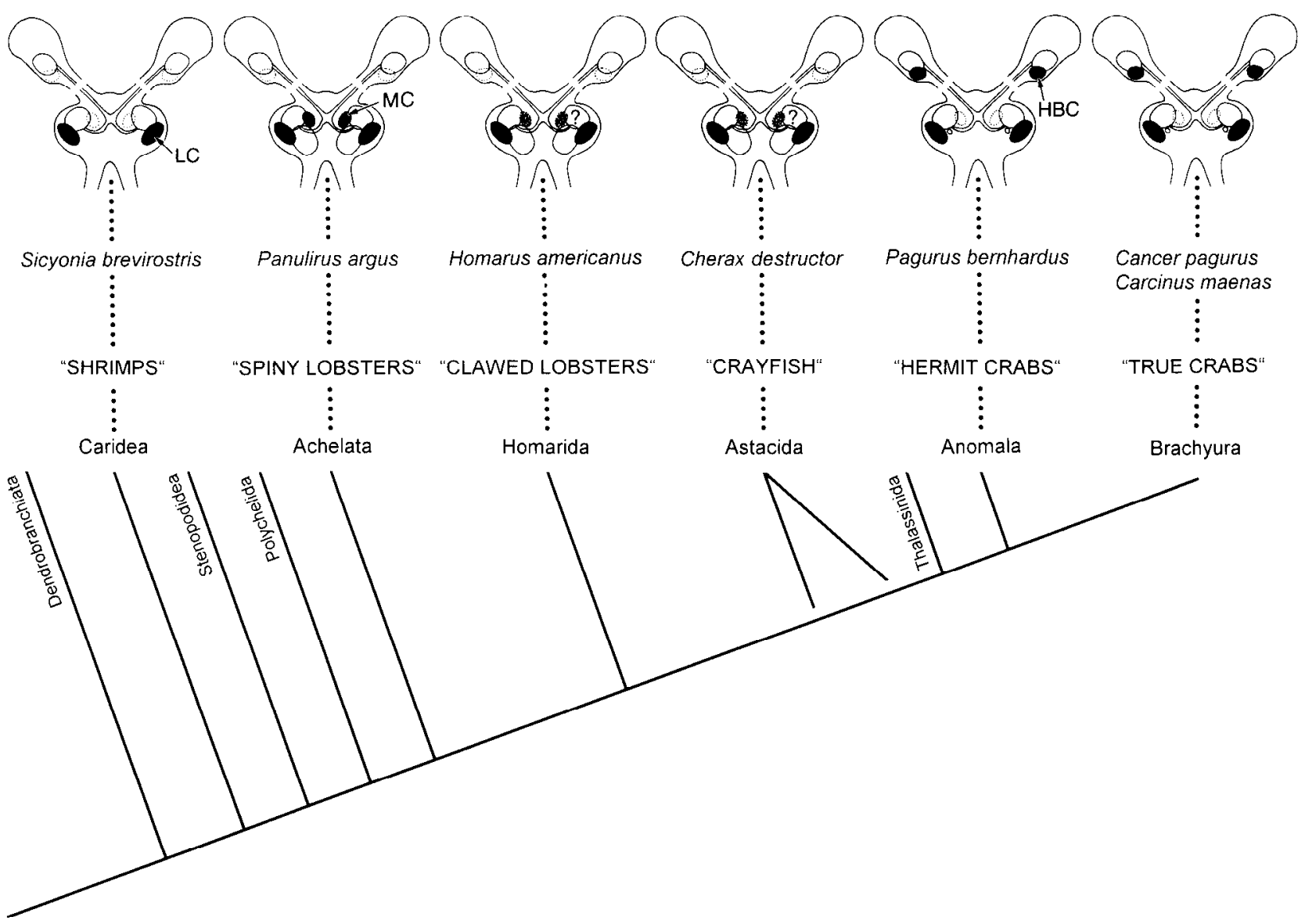

Figure 7. Occurrence of neurogenesis in the central olfactory pathway of juvenile and adult decapod crustaceans. Decapod phylogeny and terminology of taxa are according to Sandeman et al., (1993) and Scholtz and Richter (1995). Common names of taxa included in this study are given in parenthesis. Names of species studied to date (Carcinus maenas from Schmidt, 1997; Cherax destructor from Sandeman et al., 1998, and from this study, all others from this study) are given in italics. Brain morphology highlights the central olfactory pathway with olfactory lobe, accessory lobe, hemiellipsoid body, the connecting olfactory globular tracts and associated soma clusters: lateral cluster (LC), medial cluster (MC), and hemicllipsoid body cluster (IIBC). Soma clusters with typical groups of BrdU-positive nuclei are in black; in questionable cases they are dotted. Note that neuronal proliferation in the LC indicating neurogenesis among olfactory projection neurons is a common feature of adult decapod crustaceans. Proliferation in the other soma clusters of the central olfactory pathway (in the $\mathrm{MC}$ indicating neurogenesis among local interneurons of the olfactory deutocerebrum; in the HBC indicating neurogenesis among local interneurons of the hemiellipsoid body) appears to be linked to the occurrcnce (in spiny lobsters, clawed lobsters, and crayfish) and later reduction (in hermit crabs and true crabs) of the accessory lobe in the evolutionary history of decapods.

the reasons for this difference remain unclear. One possible explanation is that the adult animals tested by Sandeman et al., (1998) were significantly younger than our specimens, since the position of the BrdU-positive nuclei of the adult illustratcd in their report (in the center of the MC and at the outer edge of the LC) resembles the situation in early juveniles.

Our finding that no BrdU-positive somata were present in the LCs of three large adults of Cancer pagurus after an appropriate post-injection survival time $(5.5 \mathrm{~h})$ is the only instance so far of a negative result of this kind. In the previous study (Schmidt, 1997), all specimens of Carcinus maenas $(n=16$ ), and in this study, all other specimens of
Cancer pagurus $(n=2)$ as well as all specimens of the other species $(n=20)$ showed a typical group of BrdUpositive nuclei in each LC. This indicates that proliferation in the LC is a continuous process that apparently is not related to the molt cycle. That the negative result in Cancer pagurus occurred in very large and hence old adults suggests that, at least in some decapod species, the generation of new olfactory projection neurons may not continue for the entire life-span, but ceases in senescent animals. For some species of decapod crustaceans, enough growth data are available to allow absolute age to be estimated from body size. According to such estimates, the large specimens of Cancer pagurus, in which we did not detect BrdU- 
positive nuclei in the $\mathrm{LC}$, were at least 7 years old; whereas the smaller adults, in which we found typical groups of BrdU-positive nuclei in each LC, were about 5 years old (Gruner, 1993). In comparison, the American lobsters that showed typical groups of BrdU-positive nuclei in each LC in our experiments were at least 8 and probably more than 10 years old (Hartnoll, 1982) and the largest specimen of Panulirus argus in our study that also showed normal proliferation in the LC was at least 5 years of age (Travis, 1954).

Common features of the proliferation in the soma clusters of the central olfactory pathway in adult decapod crustaceans include the very uniform relative size, the shape, and the location of the BrdU-positive nuclei (Schmidt, 1997; this study). In each case these nuclei are among the smallest of the respective soma clusters; they are mostly spherical and thus resemble neurons; and they are located in very restricted regions of the respective soma clusters close to the neuropil. These cells apparently represent a unique type of presumptive neuronal precursor cell differing in several aspects from the neuronal precursor cells that are active during embryonic and larval development of crustaceans and insects. The latter precursor cells are neuroblasts that differentiate from the ectoderm and ganglion mother cells that arise from the neuroblasts through a series of unequal mitoses; each produces two neurons by an equal mitosis (e.g., Thomas et al., 1984; Harzsch and Dawirs, 1994). Typically, neurohlasts and ganglion mother cells are considerably larger than terminally differentiated neurons, and they are located at the outer edge of the soma clusters formed by their mitotic activity (e.g., Nordlander and Edwards, 1970; Ito and Hotta, 1992; Harzsch and Dawirs, 1994). The mitotically active precursor cells that were recently demonstrated in the LC of early postlarval crabs share these criteria and therefore are regarded as delayed ganglion mother cells (Harzsch and Dawirs, 1996). We did not find BrdU-positive nuclei resembling typical large neuroblasts or ganglion mother cells in any specimen, indicating that the mitotic activity of these cells ceases during juvenile development.

Since BrdU-positive groups of nuclei were detected in the LC of all tested species representing the major infraorders of decapod crustaceans (Fig. 7), we conclude that proliferation in the LC-and hence neurogenesis of olfactory projection neurons-most likely represents a gencral principle common to the brain of late juvenile and adult decapod crustaceans. In contrast, neurogenesis of local interneurons of the olfactory deutocerebrum and of neurons whose somata constitute the hemiellipsoid body clusters clearly is not a common feature among adult decapod crustaceans, since evidence for neuronal proliferation in the $\mathrm{MC}$ and in the HBC, respectively, occurs only in some of the tested species. In the case of the MC, we found clear evidence for neuronal proliferation only in the spiny lobster (Panulirus argus). Although we detected BrdU-positive nuclei in the
MCs of two American lobsters (Homarus americanus), it remains questionable whether they represent neuronal precursor cells. Proliferation has recently been reported (Sandeman et al., 1998) in the MCs of the Australian crayfish (Cherax destructor), but we were unable to reproduce this result. In the case of the $\mathrm{HBC}$, on the other hand, evidence for neurogenesis (i.e., clustered BrdU-positive, neuron-like nuclei) occurs only in the brachyuran crabs Carcinus maenas (Schmidt, 1997) and Cancer pagurus and in the hermit crab Pagurus bernhardus. Clearly, not enough species have been tested to exclude simple species-specific differences as the basis of this variability. However, it is striking that presumptive neurogenesis of local interneurons of the olfactory deutocerebrum appears to be restricted to species with accessory lobes (Fig. 7) - that is, glomerular neuropils of the deutocerebrum connected to the olfactory lobes (Schmidt and Ache, 1997)-whereas neurogenesis of neurons residing in the HBC occurs only in species in which the accessory lobes are thought to be reduced secondarily (Scholkz and Richter, 1995; Sandeman et al., 1993).

Clearly, the function of adult neurogenesis in decapod crustaceans and other animals remains to be determined. From the studies in decapod crustaceans, as well as from those in vertebrates and insects, it emerges that adult neurogenesis is either limited to or is at least very prominent in the central olfactory pathway (e.g., Kaplan et al., 1985; Corotto et al., 1993; Luskin, 1993; Okano et al., 1993; Cayre et al., 1994, 1996; Schmidt, 1997). The olfactory pathway also is the only sensory pathway in which primary receptor neurons show a lifelong, continuous turnover. This has been known for vertebrates including mammals for many years (e.g., Graziadei, 1973) and recently was also found for a decapod crustacean, Cherax destructor (Sandeman and Sandeman, 1996). It seems reasonable to speculate that neurogenesis in the olfactory pathway of the adult brain may be linked to the continuous turnover of olfactory receptor neurons in the periphery. This could allow a lifelong "adaptation" of the olfactory system to ever-changing olfactory environments and would be advantageous for longlived animals such as most vertebrates and decapod crustaceans.

\section{Acknowledgments}

This study was supported in part by grants from the Deutsche Forschungsgemeinschaft (Schm 738/4-1; Ha 2540/1-1). We wish to thank Dr. B. W. Ache (Whitney Laboratory, University of Florida) for providing lab space and spiny lobsters, and Dr. J. Nunez (Whitney Laboratory, University of Florida) for providing rock shrimp.

\section{Literature Cited}

Bayer, S. A. 1982. Changes in the total number of dentate granule cells in juvenile and adult rats: a correlated volumetric and $3 \mathrm{H}$-thymidine autoradiographic study. Exp. Brain Res. 46: 315-323. 
Bieber, M., and D. Fuldner. 1979. Brain growth during the adult stagc of a holometabolous insect. Naturwissenschaften 66: 426 .

Blaustein, D. N., C. D. Derby, R. B. Simmons, and A. C. Beall. 1988. Structure of the brain and medulla terminalis of the spiny lobster Panulirus argus and the crayfish Procambarus clarkii, with an emphasis on olfactory centers. J. Crust. Biol. 8: 493-519.

Boeckh, J., K. D. Ernst, H. Sass, and U. Waldow. 1984. Anatomical and physiological characteristics of individual neurons in the central antennal pathway of insects. I. Insect Physiol. 30: 15-26.

Cayre, M., C. Strambi, and A. Strambi. 1994. Neurogenesis in an adult insect brain and its hormonal control. Nature 368: 5759.

Cayre, M., C. Strambi, P. Charpin, R. Augier, M. R. Meyer, J. S. Edwards, and A. Strambi. 1996. Neurogenesis in adult insect mushroom bodies. J. Comp. Neurol. 371: 300-310.

Corotto, F. S., J. A. Henegar, and J. A. Maruniak. 1993. Neurogenesis persists in the subependymal layer of the adult mouse brain. Neurosci. Lett. 149: 111-114.

Crespo, D., B. B. Stanfield, and W. M. Cowan. 1986. Evidence that late-generated granule cells do not simply replace earlier formed neurons in the rat dentate gyrus. Exp. Brain Res. 62: 541-548.

Davis, R. L. 1993. Mushroom bodies and Drosophila learning. Neuron 11: $1-14$.

Fahrbach, S. E., J. L. Strande, and G. E. Robinson. 1995. Neurogenesis is absent in the brains of adult honey bees and does not explain behavioral neuroplasticity. Neurosci. Lett. 197: 145-148.

Graziadei, P. P. C. 1973. Cell dynamics in the olfactory mucosa. Tissue Cell 5: 113-131.

Gruner, H.-E., ed. 1993. Lehrbuch der speziellen Zoologie. Band l: Wirbellose Tiere. 4. Teil: Arthropoda (ohne Insecta). Gustav Fischer Verlag, Stuttgart.

Hartnoll, R. G. 1982. Growth. Pp. 111-196 in The Biology of Crustacea. Vol. 2. Embryology, Morphology, and Genetics, L. G. Abele. ed. Academic Press, New York.

Harzsch, S., and K. R. Dawirs. 1994. Neurogenesis in larval stages of the spider crab Hyas araneus (Decapoda, Brachyura): proliferation of neuroblasts in the ventral nerve cord. Roux's Arch. Dev. Biol. 204: 93-100.

Harzsch, S., and R. R. Dawirs. 1996. Neurogenesis in the developing crab brain: postembryonic generation of neurons persists beyond metamorphosis. J. Neurobiol. 29: 384-398.

Ito, K., and Y. Hotta. 1992. Proliferation pattern of postembryonic neuroblasts in the brain of Drosophila melanogaster. Dev. Biol. 149: $134-148$.

Kaplan, M. S., and J. W. Hinds. 1977. Neurogenesis in the adult rat: electron microscopic analysis of light radioautographs. Science 197: 1092-1094.

Kaplan, M. S., N. A. McNelly, and J. W. Hinds. 1985. Population dynamics of adult-formed granule neurons of the rat olfactory bulb. J. Comp. Neurol. 239: 117-125.

Kuhn, H. G., H. Dickinson-Anson, and F. H. Gage. 1996. Neurogenesis in the dentate gyrus of the adult rat: age-related decrease of neuronal progenitor proliferation. J. Neurosci. 16: 2027-2033.

Luskin, M. B. 1993. Restricted proliferation and migration of postnatally generated neurons derived from the subventricular zone. Neuron 11: $173-189$.

Mellon, D., Jr., V. Alones, and M. D. Lawrence. 1992. Anatomy and fine structure of neurons in the deutocerebral projection pathway of the crayfish olfactory system. J. Comp. Neurol. 321: 93-111.

Menzel, R., C. Durst, J. Erber, S. Eichmüller, M. Hammer, H. Hildebrandt, J. Mauelshagen, U. Müller, H. Rosenboom, J. Rybak, S. Schäfer, and A. Scheidler. 1994. The mushroom bodies in the honeybee: from molecules to behavior. Pp. 81-102 in Fortschritte der Zoologie, Vol. 39. Neural Basis of Behavioural Adaptations, K. Schildberger and N. Elsner, eds. Gustav Fischer Verlag, New York.

Morshead, C. M., B. A. Reynolds, C. G. Craig, M. W. McBurney, W. A. Staines, D. Morassutti, S. Weiss, and D. Van der Kooy. 1994. Neural stem cells in the adult mammalian forebrain: a relatively quiescent subpopulation of subependymal cells. Neuron 13: 1071-1082.

Nordlander, R. H., and .I. S. Edwards. 1970. Postembryonic brain development in the monarch butterfly, Danaus plexippus plexippus L. III. Morphogenesis of centers other than the optic lobes. Wilhelm Roux' Arch. 164: 247-260.

Okano, H. J., D. W. Pfaff, and R. B. Gibbs. 1993. RB and Cdc2 expression in brain: correlations with ${ }^{3} \mathrm{H}$-thymidine incorporation and neurogenesis. J. Neurosci. 13: 2930-2938.

Paton, J. A., and F. N. Nottebohm. 1984. Neurons generated in the adult brain are recruited into functional circuits. Science 225: 10461048.

Purves, D. 1988. Body and Brain. A Trophic Theory of Neuronal Connections. Harvard University Press, Cambridge.

Raymond, P. A., and S. S. Easter, Jr. 1983. Postembryonic growth of the optic tectum in goldfish. I. Location of germinal cells and numbers of neurons produced. J. Neurosci. 3: 1077-1091.

Sandeman, R. E., and D. C. Sandeman. 1996. Pre- and postembryonic development, growth and turnover of olfactory receptor neurons in crayfish antennules. J. Exp. Biol. 199: 2409-2418.

Sandeman, D., R. Sandeman, C. Derby, and M. Schmidt. 1992. Morphology of the brain of crayfish, crabs, and spiny lobsters: a common nomenclature for homologous structures. Biol. Bull. 183: 304-326.

Sandeman, D. C., G. Scholtz, and R. E. Sandeman. 1993. Brain evolution in decapod Crustacea. J. Exp. Zool. 265: 112-133.

Sandeman, R., D. Clarke, D. Sandeman, and M. Manly. 1998. Growth-related and antennular amputation-induced changes in the offactory centers of crayfish brain. J. Neurosci. 18: 6195-6206.

Schmidt, M. 1997. Continuous neurogenesis in the olfactory brain of adult shore crabs, Carcinus maenas. Brain Res. 762: 131-143.

Schmidt, M., and B. W. Ache. 1997. Immunocytochemical analysis of glomerular regionalization and neuronal diversity in the olfactory deutocerebrum of the spiny lobster. Cell Tissue Res. 287: 541-563.

Scholtz, G., and S. Richter. 1995. Phylogenetic systematics of the reptantian Decapoda (Crustacea, Malacostraca). Zool. J. Linn. Soc. 113: $289-328$.

Technau, G. M. 1984. Fiber number in the mushroom bodies of adult Drosophila melanogaster depends on age, sex and experience. J. Neurogenet. 1: 113-126.

Thomas, J. B., M. J. Bastiani, M. Bate, and C. S. Goodman. 1984. From grasshopper to Drosophila: a common plan for neuronal development. Nature 310: 203-207.

Travis, D. F. 1954. The molting cycle of the spiny lobster Panulirus argus Latreille. I. Molting and growth in laboratory-maintained individuals. Biol. Bull. 107: 433-450. 